\title{
Turismo de Base Comunitária: \\ uma possibilidade pensada com moradores do Bairro Alto do Cruzeiro, em São Luiz do Paraitinga/SP
}

Community Base Tourism: a possibility thought with the residents of Alto do Cruzeiro neighborhood, in São Luiz do Paraitinga/SP

Turismo de Base Comunitaria: una posibilidad pensada junto a los habitantes del barrio Alto do Cruzeiro, São Luiz do Paraitinga/SP

http://dx.doi.org/10.18472/cvt.16n3.2016.1175

Mariana Tomazin 〈mariana_tomazin@hotmail.com >

Centro de Excelência em Turismo da Universidade de Brasília (CET/UnB), Brasília, DF, Brasil.

Patrícia Alves Ramiro < patriciaalvesramiro@gmail.com >

Universidade Federal da Paraíba (UFPB), João Pessoa, PB, Brasil.

CRONOLOGIA DO PROCESSO EDITORIAL

Recebimento do artigo: 16-nov-2015

Aceite: 05-ago-2016

FORMATO PARA CITAÇÃO DESTE ARTIGO

TOMAZIN, M.; RAMIRO, P. A. Turismo de Base Comunitária: uma possibilidade pensada com os moradores do Bairro Alto do Cruzeiro, em São Luiz do Paraitinga/SP. Caderno Virtual de Turismo. Rio de Janeiro, v. 16, n. 3, p. 155-171, dez. 2016.

REALIZAÇÃO

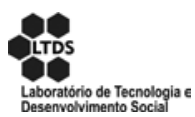

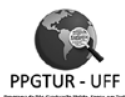

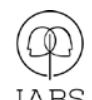

APOIO INSTITUCIONAL

EDIÇÃO

PATROCÍNIO

COPPE

UFR]

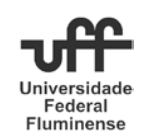

EDITORค 


\section{RESUMO}

São Luiz do Paraitinga, estância turística localizada no estado de São Paulo, é conhecido por seus casarões do século XIX e suas festas populares. Em 2010, o município sofreu com a maior enchente de sua história, quando viu parte de seu patrimônio arquitetônico ruir. Doravante, o período de reconstrução pós-enchente reforçou o olhar de gestores públicos e de alguns segmentos sociais locais para a relevância do turismo para o desenvolvimento local. Em consonância com o contexto vivido, o presente trabalho teve como objetivo pensar com os moradores do bairro Alto do Cruzeiro suas potencialidades para o planejamento de um turismo mais sustentável, visto que vivem em condições mais precárias no que se refere ao acesso a bens e serviços. Com base na metodologia da história oral e na realização de um diagnóstico rápido participativo pode-se constatar a existência de um bairro com fortes vínculos de amizade e portador de um sentimento enraizado de pertencimento ao lugar, características que, somadas às manifestações culturais identificadas, poderão servir de suporte para o desenvolvimento do turismo de base comunitária no bairro.

Palavras-chave: Turismo de base comunitária. Alto do Cruzeiro. São Luiz do Paraitinga.

\section{ABSTRACT}

São Luiz do Paraitinga, tourist resort, located in the state of São Paulo, is known for its mansions of the nineteenth century and its popular festivities. In 2010, the city suffered with the biggest flood in its history, when it saw part of its architectural heritage fall apart. From now on, the post-flood reconstruction period reinforced the look of public officials and some local social groups towards the importance of the tourism to local development. According to the lived context, this study aimed to think together with the inhabitants of Alto do Cruzeiro neighborhood, about their potential for planning a more sustainable tourism, since they live in precarious conditions and with limited access to goods and services. Based on the methodology of oral history and conducting a participatory fast diagnosis it was possible to observe the existence of a neighborhood with strong bonds of friendship and carrying a rooted sense of belonging to the place, features, together with the identified cultural events, may provide support for the development of community-based tourism in the district.

Keywords: Comunity Base Tourism. Alto do Cruzeiro. São Luiz do Paraitinga.

\section{RESUMEN}

São Luiz do Paraitinga, estancia turística ubicada en el estado de São Paulo, es conocida por la arquitectura de las casas del siglo XIX y también por sus fiestas populares. En 2010, el municipio sufrió con la más grande inundación de su historia, cuando vio parte de su patrimonio arquitectónico desaparecer. De ahora en adelante, el periodo de reconstrucción después de la inundación reforzó la visión de gestores públicos y de algunos segmentos sociales locales para la importancia del turismo para el desarrollo local. En consonancia con el contexto vivido, el presente trabajo tuvo como objetivo pensar con los habitantes del barrio Alto do Cruzeiro sus potencialidades para la planificación de un turismo más sustentable, dado que, visiblemente, viven en condiciones más precarias referente al acceso a bienes y servicios. Con base en la metodología de la historia oral y en la realización de un diagnóstico rápido participativo se puede constatar la existencia de un barrio con fuertes vínculos de amistad y portador de un sentimiento enraizado de pertenencia al lugar, características que, sumadas a las manifestaciones culturales identificadas, podrán servir de soporte para el desarrollo del turismo de base comunitaria en el barrio.

Palabras clave: Turismo de Base Comunitaria. Alto do Cruzeiro. São Luiz do Paraitinga. 


\section{Introdução}

São Luiz do Paraitinga, município localizado na região conhecida como Vale do Paraíba paulista, a apenas 170 quilômetros da capital do estado de São Paulo, é conhecido por seus casarões do século XIX, sua paisagem natural junto a áreas de Mata Atlântica e por suas festas populares, especialmente, seu carnaval e Festa do Divino. Em 2010, teve grande parte de seu patrimônio arquitetônico destruído por uma enchente. Naquele momento, segundo dados do censo realizado pelo Instituto Brasileiro de Geografia e Estatística (IBGE), possuía uma população de 10.397 habitantes, sendo 6.180 residentes na zona urbana. Assim como outras cidades da região, São Luiz do Paraitinga teve seu apogeu econômico e social com a cafeicultura no século XIX, o que justifica o fato de algumas casas térreas e sobrados terem sido tombados pelo Conselho de Defesa do Patrimônio Histórico, Arqueológico, Artístico e Turístico do Estado (Condephaat) em $1982^{1}$. O reconhecimento desse patrimônio como atrativo turístico rendeu ao município o título de Estância Turística em 2002, o qual, como esclarecem Campos e Delamaro (2011, p. 78) "[...] lhe garante a possibilidade de receber aportes financeiros voltados especificamente para fomentar o turismo".

Todavia, do ponto de vista geográfico, observa-se que a maior parte do patrimônio material concentra-se no perímetro urbano da cidade, visto que o local teve seu ordenamento iniciado a partir da praça central $^{2}$. Essa concentração dos atrativos materiais incide nitidamente nas práticas de turismo no centro histórico. Grande parte dos olhares (e, consequentemente, dos incentivos) é direcionada para a área. Manifestações populares, eventos, museus, restaurantes e muitas pousadas e hotéis ali estão. Esse cenário de concentração nos mostra a fragmentação estabelecida no território como um todo, gerando uma população de excluídos dos benefícios do turismo que irão compor aquilo que chamamos de entorno, ou seja, uma área que tangencia o local de reprodução do capital e que se apresenta "esquecida" perante as políticas de incentivo.

Pensando nisso, este trabalho tem como propósito discutir o turismo de base comunitária como uma alternativa para os moradores do bairro Alto do Cruzeiro, morro do qual se vê (e se é visto) do centro histórico de São Luiz do Paraitinga. Essa proximidade física entre os espaços, em oposição à distância quanto ao acesso aos benefícios da atividade turística, serviu de inquietação inicial para o desenvolvimento desta pesquisa. Composto por um número representativo de casas, o bairro Alto do Cruzeiro é parte integrante da paisagem local, embora apareça como se fosse o fundo de um cartão-postal do centro histórico. Ainda que perceptível, aparece distante por não dialogar com a realidade apresentada no centro histórico, deixando transparecer uma situação econômica de características díspares entre o morro e centro.

Diante desse cenário, e pensando na possibilidade de construção de maior diálogo entre os espaços, questionamos se o turismo, entendido como um fenômeno social e complexo, não poderia, dentro de uma perspectiva de planejamento integral, superar essa distância estabelecida entre centro e morro?

Para melhor compreensão desta pesquisa, há que se considerar a excepcionalidade do momento de sua realização. Em 2011, quando as autoras estiveram no local, o município de São Luiz do Paraitinga estava no auge do momento de reconstrução pós-enchente. A destruição total de parte de seu patrimônio

\footnotetext{
1 Em 2010, ocorreu o tombamento pelo Instituto do Patrimônio Histórico e Artístico Nacional - Iphan, o que corroborou a relevância patrimonial da cidade (cf. CAMPOS, 2011).

2 Relatos históricos escritos por Mário Aguiar que narram esse início da cidade foram publicados na forma de crônicas sobre São Luiz do Paraitinga na primeira metade do século XX. Republicados após a enchente pela Associação dos Amigos para Recuperação e Preservação do Patrimônio Histórico e Cultural de São Luiz do Paraitinga (cf. AGUIAR, 2011).
} 
arquitetônico conseguiu chamar atenção da mídia, de políticos, de órgãos públicos e pesquisadores. Mas, principalmente, como Santos (2015), morador e historiador, deixou transparecer de maneira bastante interessante em sua tese de doutorado, gerou um sentimento de pertencimento e de luta nos moradores locais ansiosos por reconstruir a cidade. Este período reforçou o olhar de gestores públicos e de alguns segmentos sociais para a relevância do turismo para o desenvolvimento local. Além de buscar os reparos aos danos materiais causados pela força da água, foi também o momento ideal para se repensar em propostas que solucionassem problemas antigos ainda vigentes, como a exclusão social dos moradores do Alto do Cruzeiro das práticas turísticas locais.

Foi nesse contexto que, em uma parceria entre o poder público e a universidade, surgiu o "Programa Unesp para Desenvolvimento Sustentável de São Luiz do Paraitinga” (BIZELLI; ALVES, 2011)3 , por meio do qual pôde-se realizar esse trabalho coletivo com moradores do Alto do Cruzeiro com o intuito de pensar com eles (e não para eles) a potencialidade do bairro para a implantação do turismo de base comunitária. Para tanto, foram adotadas diferentes estratégias de ação conforme objetivos a serem alcançados. Em um primeiro momento, interessou-nos conhecer a história do bairro e sua formação. E, assim, o uso da metodologia da história oral foi de fundamental importância para a reconstrução das trajetórias, individuais e coletivas, de seus moradores. Posteriormente, realizou-se um diagnóstico rápido participativo para construção de um panorama da realidade vivida pelos moradores e identificação dos potenciais atrativos do bairro.

A metodologia adotada pelas autoras atuou em conformidade com as ideias de Paulo Freire (1983), que considera tarefa fundamental do "educador/extensionista", educar e educar-se. Não cabe, nessa perspectiva, a postura unilateral de transmissão do conhecimento, mas, sim, a valorização de uma construção dialógica, que permita a troca e valorize as diferentes formas de conhecimentos. Acreditamos que com o uso de abordagens baseadas em metodologias participativas garantimos a existência de relações mais humanizadas, com a alteração necessária na postura do educador/mediador, o qual garante que o grupo social envolvido na proposta tenha um papel ativo durante todo o processo de reflexão. Obviamente, não defendemos que o educador/mediador seja alguém neutro durante esse processo. O principal ponto reside na capacidade de construção coletiva em um ambiente de troca de conhecimentos, a qual se, por um lado, não impõe formatos "corretos" aos interessados, por outro, informa-os e dialoga com eles sobre as possibilidades existentes. Assim, como esclarece Brandão (1999), nessa perspectiva surge a necessidade da participação do outro para construção do resultado.

\section{A enchente de 2010: um marco na memória coletiva do município}

As enchentes fazem parte da vida do povo luizense nos períodos de chuva, em função da proximidade da cidade com as águas do Rio Paraitinga, as quais, geralmente, atingem somente as casas do lado baixo da cidade (CAMPOS, 2011; AB'SABER, 2011). Inclusive, conforme alertam Souza (2010) e Silva (2011), a cidade foi erguida em áreas de risco, crescendo perto da margem do rio. O município possui registros de enchente desde o século XIX, quando, em 1863, alguns prédios foram destruídos com a força da água. Em 1967, ocorreram duas enchentes no começo do ano, sendo que, em ambas, o rio subiu 5,80 metros. A partir dessas ocorrências as inundações da cidade se tornaram periódicas na parte baixa e, entre 1980 a

30 presente trabalho é parte do referido programa composto por equipe multidisciplinar, coordenado pelo prof. Dr. José Xaides de Sampaio Alves, professor do Departamento de Arquitetura, Urbanismo e Paisagismo da Unesp, Campus de Bauru. 
2011, a prefeitura decretou por três vezes estado de calamidade pública (CAMPOS, 2011). Mas, a pior de todas elas ocorreu recentemente.

No dia 31 de dezembro de 2009 choveu praticamente o dia inteiro na cidade e, no dia seguinte, $1^{\circ}$ de janeiro, as águas subiram muito e, à tarde, quase toda praça da Igreja Matriz, localizada no centro histórico, já estava inundada. A partir da noite e na madrugada do dia 2 de janeiro de 2010, o volume de água do rio ficou cerca de 12 metros acima do nível normal, conforme ilustra a Figura 2. O acúmulo de chuvas intensas no município por quatro dias e o represamento do Rio do Chapéu, o qual deságua no Rio Paraitinga, foram, segundo Souza (2010), fatores determinantes para a enchente.

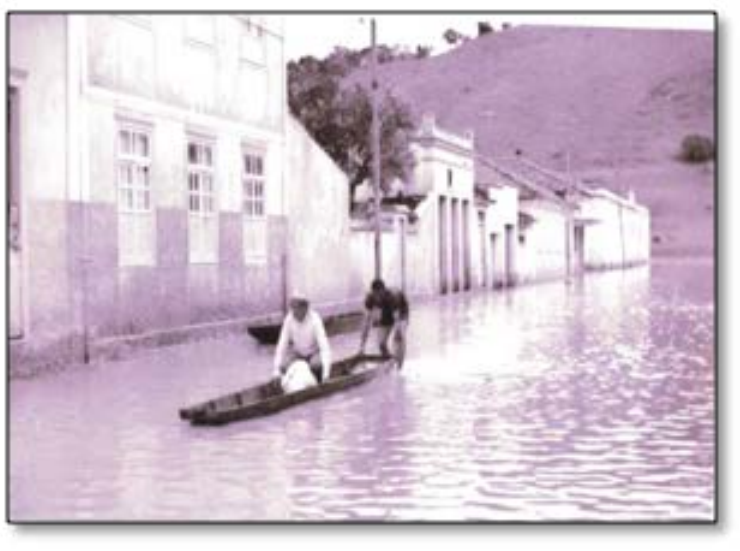

Figura 1 - Enchente de 1967 Fonte: (Coleção Nenê Coringa)

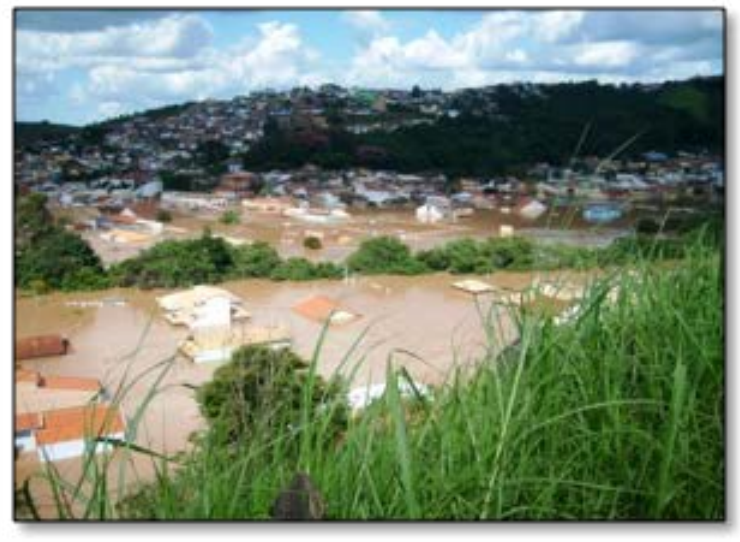

Figura 2 - Enchente de 2010 Fonte: (Foto de Irene Ferreira)

Para serem salvas, as pessoas da parte inundada foram para as partes mais elevadas do município, entre elas, o bairro Alto do Cruzeiro. Como expõe Ab'Saber:

[...] um dos acontecimentos solidários foi a ajuda dos habitantes mais pobres dos morros para os mais bem-aquinhoados, residentes na baixada central. [...] Um bom número de pessoas foi para o patamar de morro da casa de Oswaldo Cruz, outras subiram pelas ladeiras de terraços e colinas, asilando-se em casas de parentes e amigos (AB'SABER , 2011, p.172).

A solidariedade naquele momento difícil aproximou as diferentes classes sociais de São Luiz do Paraitinga que, juntas, vivenciaram a destruição de um imenso patrimônio arquitetônico. Um de seus moradores descreve em entrevista concedida às autoras como o desespero assolou a cidade inteira:

Ah eu vi a enchente desde o comecinho até o final. Daqui de cima a gente via tudo, casa caindo, barulho de água... só água mesmo, como se fosse o mar, não dormia... não tinha água, não tinha luz, quando chegava a noite era um desespero, era berro, era choro, sabe? (André L. C., 41 anos, morador do Alto do Cruzeiro, 2011).

Muitos moradores ficaram ilhados em suas casas, com a esperança da água parar de subir, o que não aconteceu, pois a enchente só se agravava e chegou ao segundo andar dos sobrados. O corpo de bombeiros demorou a chegar, então as operadoras de rafting da cidade colocaram seus equipamentos na água e começaram a realizar o resgate das pessoas, com a ajuda de voluntários. Isso foi determinante para que todos sobrevivessem a essa tragédia, pois nenhuma vida foi deixada para trás (SANTOS; RICCI, 2010; CAMPOS, 2011). A cidade ficou destruída, praticamente todo o comércio local e os casarões do centro 
histórico; cheiro ruim, muito barro, móveis destruídos, entulho e uma enorme quantidade de lixo foram as consequências da passagem avassaladora das águas do rio na cidade. Totalizando em 83 imóveis danificados pelas águas, 18 que desabaram e 65 que ficaram com as estruturas afetadas. Além do grande marco simbólico que foi a queda da Igreja Matriz (SANTOS, 2015; SOUZA, 2010).

A solidariedade dos munícipes uns com outros foi tamanha que rompeu algumas barreiras que separam, física e simbolicamente, pobres e ricos. Como narrou uma entrevistada ${ }^{4}$, foi "todo mundo muito solidário com o povo daqui, não queria saber se o outro era mais do que o outro, todo mundo ficou igualado, todo mundo se serviu". Por ouvirmos repetidas vezes esse tipo de depoimento, acreditamos que o momento histórico vivido, apesar da tragédia material causada, poderia ser percebido como uma oportunidade excepcional para início da discussão de um novo planejamento do turismo em São Luiz do Paraitinga. A solidariedade vigente naquela situação poderia, ao menos do ponto de vista hipotético, servir de estímulo para a construção de um cenário turístico mais equitativo, em consonância com a heterogeneidade dos atores sociais do município.

\section{Turismo, planejamento e inclusão social}

O turismo, assim como toda e qualquer atividade humana, proporciona impactos. Desse modo, necessita de planejamento minucioso a fim de potencializar os de cunho positivos e minimizar os negativos, o que implica no entendimento do turismo como algo complexo, amplo e dinâmico, que abrange aspectos sociais, políticos, culturais, econômicos e ambientais. Levando em consideração que o turismo surge no mundo moderno e, portanto, capitalista, é frequente vermos sua redução à óptica econômica, que valoriza os recursos financeiros oriundos de suas práticas sem a devida preocupação aos possíveis impactos negativos, quer sejam ao meio ambiente ou às culturas locais. Assim, o turismo praticado sem planejamento sustentável pode significar agravamento de desigualdades e destruição ambiental, ainda que possa ser considerado como significativo do ponto de vista econômico de um município, região ou país. A concentração de renda que pode ser gerada pelo turismo, resulta, na maioria dos casos, em exclusão social de muitos que, em decorrência do planejamento inadequado (ou até mesmo ausente), vêem-se isolados do desenvolvimento promovido.

Na prática, isso significa que são obrigados, conforme cada contexto vivenciado, a migrarem para locais mais afastados e/ou a se submeterem a empregos temporários, geralmente com baixa remuneração, nos empreendimentos do trade turístico. É por esse motivo que Beni (2006, p. 45) coloca que "um dos grandes desafios do turismo é proporcionar aos núcleos receptores não somente desenvolvimento econômico, mas também social". Todavia, cada vez mais, cresce a perspectiva alternativa que defende a possibilidade de uma prática do turismo mais justa e, portanto, menos concentradora dos benefícios. A consolidação na década de 1980, ainda que tardia, de uma consciência ambientalista que se posiciona de maneira intensa contra impactos devastadores ao meio ambiente, soma-se à defesa da tese de que são as populações locais, quer sejam comunidades tradicionais ou não, as que melhor expressam modos de vida mais sustentáveis, pois carregam em sua cultura o sentimento da preservação dos bens materiais e simbólicos em prol das futuras gerações. Como consequência, atualmente, vemos uma fase de valorização das culturas locais, entendidas como um conjunto de práticas culturais de grupos historicamente marginalizados.

4 Depoimento dado por Maria J., 42 anos, moradora do Alto do Cruzeiro, 2011. 
Se, no início da prática do turismo, tudo (ou quase tudo) poderia parecer exótico ao olhar dos viajantes, o mundo globalizado de hoje apresenta uma homogeneização dos espaços das grandes cidades, o que requer, por sua vez, a descoberta de subculturas que foram capazes de se manterem, ainda que por meio de grande potencial de invenção das tradições, para usar expressão de Hobsbawm (1984). A diversidade de espaços passíveis ao recebimento de turistas no mundo contemporâneo impõe que para se pensar no desenvolvimento do setor deve-se evitar uma visão fragmentada do turismo. Como mostram Gastal e Moesch (2007, p. 45):

Uma política pública de Turismo deve ter como concepção o Turismo como um sistema aberto, orgânico e complexo que se coloque como atividade multissetorial, cuja execução deve, necessariamente, incorporar visões multidisciplinares, multiculturais e multissociais.

Será através dessa incorporação de visões diferenciadas que os diversos atores sociais que compõem um determinado lugar poderão construir uma proposta de recepção de turistas capaz de deixar transparecer sua heterogeneidade cultural e, assim, alcançar uma distribuição mais justa dos benefícios, materiais e simbólicos, do fenômeno turístico. Entendemos que o turismo, conforme a tese de humanização apresentada por Krippendorf (2009), deve ser visto como uma possibilidade de inclusão social no processo de desenvolvimento humano e, assim, necessita de uma política que tenha o ser humano como sustentáculo. O turismo não deve centrar-se exclusivamente nas finalidades econômicas e técnicas, mas deve respeitar todas as necessidades postas pelos atores sociais envolvidos, não se restringindo apenas a uma parcela seletiva.

Nesse sentido, defendemos a ideia de que o turismo tradicional e o turismo de base comunitária podem ser percebidos como complementares, afinal, atendem às necessidades de diferentes grupos das sociedades receptoras. Até mesmo porque, como veremos a seguir, o turismo de base comunitária é um dos modelos possíveis e depende de determinadas características socioculturais para ser efetivado com sucesso.

\section{0 turismo de base comunitária}

Como, geralmente, há a exclusão de comunidades locais em participar das decisões e do planejamento do turismo, embora sejam direta e indiretamente afetadas em seu cotidiano, um novo eixo de turismo surge. Denominado de turismo de base comunitária, esse modelo de turismo é:

Aquele no qual as populações locais possuem o controle efetivo sobre o seu desenvolvimento e gestão, e está baseado na gestão comunitária ou familiar das infraestruturas e serviços turísticos, no respeito ao meio ambiente, na valorização da cultura local e na economia solidária (TUCUM, 2008 apud SANSOLO; BURSZTYN, 2009, p. 147).

Nesta proposta, mais do que um segmento, podemos dizer que sua diferenciação em relação ao turismo "tradicional" reside no fato de serem os residentes os responsáveis pelo controle e gestão do turismo praticado. São os próprios moradores de determinado local que devem se encarregar de todo o planejamento até a gestão dos arranjos produtivos. O turismo de base comunitária se inicia, portanto, como uma possibilidade de conquista de melhorias para grupos comumente excluídos do trade turístico. Melhorias que podem ser alcançadas tanto sob o aspecto econômico, via geração de renda, quanto pelo cultural, por meio do fortalecimento de identidades ameaçadas pela modernidade e/ou no aspecto ambiental, pela abertura de novas possibilidades para a preservação ambiental de territórios. 
O turismo de base comunitária visa o encontro de novas oportunidades para o lugar por meio do envolvimento participativo dos moradores em uma abordagem coletiva, não individualista. Nesse tipo de turismo, as gestões integradas dos arranjos produtivos são comunitárias. Segundo Coriolano (2009), os projetos de turismo de base comunitária devem garantir melhorias das condições de vida local e oferecer a visitados e turistas uma forma mais digna de interação social. Por essa característica, ainda que não possamos afirmar que o turismo de base comunitária seja associado somente à pobreza e exclusão social, visto que é mais uma maneira alternativa de gestão dos empreendimentos, é mais facilmente encontrado em comunidades tradicionais, como em aldeias indígenas e comunidades quilombolas, além de locais habitados por grupos sociais marginalizados, como algumas comunidades rurais e favelas nos centros urbanos ${ }^{5}$.

Concordamos com Irving (2009) quando afirma que a palavra comunidade utilizada nesse caso aproxima-se do sentido de comum, de coletivo e, dessa maneira, não apresenta necessariamente um caráter de classe social. Todavia, são os atores sociais menos favorecidos na sociedade que permanecem naquilo que convencionou-se chamar de entorno do desenvolvimento turístico e os que parecem possuir maior capacidade de atuação em prol de um objetivo comum, coletivo. Do ponto de vista geográfico, podem estar fisicamente separados do lugar turístico, como é o caso das periferias urbanas ou de pescadores que são expropriados de suas terras em consequência da especulação imobiliária para instalação de estabelecimentos do turismo "sol e praia", ou podem conviver lado a lado com a região turística, como é o caso das favelas cariocas e do bairro de Alto Cruzeiro desta pesquisa, por exemplo.

Doravante, é importante frisar que o turismo de base comunitária deve significar encontro e oportunidade de experiência compartilhada e não deve ser visto através de uma interpretação simplista e estereotipada, que o reduz a um grupo social desfavorecido que recebe "outsiders" curiosos e ávidos pelo exotismo em seu convívio cotidiano (IRVING, 2009). Como esclarece Jovchelovitch (1998 apud Irving, 2009, p. 111) "é no encontro que saberes sociais se produzem e são renovados laços de diferença e solidariedade, que envolvem o sentido de comunidade e pertencimento".

De todo modo, cabe reforçar que o turismo, em qualquer de suas formas de expressão e intervenção, é responsável por interferir na dinâmica socioambiental de seu destino. O que diferencia o turismo de base comunitária de outros formatos reside no fato de que o turismo comunitário visa o desenvolvimento local a partir de uma vontade coletiva de recebimento de visitações que seja capaz de atender aos anseios da população local, com potencialidade para fortalecimento dos vínculos sociais do lugar, valorização da identidade e, portanto, da cultura local, além de viabilizar uma oportunidade de desenvolvimento econômico. Pessoas que geralmente são objetos de atração turística ofertada por outros empreendedores, passam, nesse modelo, a ser sujeitos dentro desse novo cenário. Isso não significa que não possa haver a participação ativa de atores sociais exógenos, os quais atuam (ou deveriam atuar) de maneira colaborativa para o planejamento e gestão dos projetos em andamento. Como nos alerta Irving:

Evidentemente que o turismo de base comunitária resulta de uma demanda direta dos grupos sociais que residem no lugar turístico, e que mantêm com esse território uma relação cotidiana de dependência e sobrevivência material e simbólica. Assim, não é possível imaginar uma iniciativa de turismo de base comunitária resultante de uma decisão externa, de uma intervenção exógena à realidade e aos modos de vida locais. Nesse caso, embora frequentemente atores externos funcionem como "indutores" do turismo de base comunitária, se a iniciativa não tiver

\footnotetext{
5 Ainda que incipientes e em busca dos conhecimentos teóricos mais adequados para seu entendimento, diversos pesquisadores vêm tentando compreender os formatos existentes e suas possibilidades e limitações para esses grupos. Entre alguns, podemos citar os estudos de Grünewald (2000) sobre o turismo étnico na aldeia Pataxó na Bahia, as pesquisas de Schneider (2006) e Ramiro (2015) sobre a abertura de propriedades rurais da agricultura familiar para turistas, e Freire-Medeiros (2009) sobre o turismo em favelas no Rio de Janeiro.
} 
motivação endógena e expressar o desejo dos grupos sociais locais, ela certamente não atenderá às demandas de desenvolvimento local e nem contribuirá para o protagonismo social, condição essencial para esse tipo de turismo (IRVING, 2009, p. 112).

Geralmente, no caso brasileiro, o que vemos são organizações não governamentais nacionais e estrangeiras, projetos de extensão universitária e alguns funcionários do setor público atuando em parceria com os grupos sociais para a execução do turismo comunitário. Mas, para que seja bem-sucedida, uma proposta de turismo comunitário precisa ocorrer por meio de um processo ativo e autônomo que permita que a própria comunidade discuta e decida o caminho a percorrer. Para tanto, como defende Ramiro (2012), faz-se necessário que sejam capazes de refletirem coletivamente sobre seu passado, de entenderem seu presente e, assim, terem condições para planejarem seu futuro.

Embora do ponto de vista econômico esse modelo de turismo não deva ser tratado de forma utópica ou como meio de expressão revolucionária contra os padrões econômicos atuais (RIBEIRO, 2008), ele aproxima-se dos valores propagados pela economia solidária, onde a união entre pessoas consideradas "iguais" visa a conquista de uma vida melhor. Para Singer (2002, p. 09), "a solidariedade na economia só pode se realizar se ela for organizada igualitariamente pelos que se associam para produzir, comerciar, consumir ou poupar. A chave dessa proposta é a associação entre iguais em vez do contrato entre desiguais". Importante destacar que essa vida melhor não se resume apenas ao sentido de que "possam consumir mais", mas também pela construção mais saudável de laços de sociabilidade intra e interdoméstico, na liberdade de escolha por um trabalho que dê mais satisfação; no direito à maior autonomia na esfera produtiva e na obtenção de maior poder de decisão e controle sobre os anseios para a vida.

Por fim, cabe destacar que para que o turismo comunitário seja possível é preciso que, em um primeiro momento, as pessoas envolvidas tragam à tona as potencialidades de seu local de vida para a atração de visitantes. $\mathrm{O}$ autoconhecimento é, dessa maneira, a primeira etapa para o planejamento turístico comunitário. Com esse intuito, este trabalho traz o processo de identificação do potencial que foi realizado pelos moradores do bairro Alto do Cruzeiro em São Luiz do Paraitinga com a intermediação das autoras deste trabalho.

\section{Potencialidades e necessidades do Bairro Alto do Cruzeiro}

O bairro Alto do Cruzeiro, localizado na estância turística de São Luiz do Paraitinga/SP, possui como característica marcante seu local de formação, em cima de um morro. Assim, é possível visualizar o bairro com muita facilidade quando se passa pela estrada que liga o município de Taubaté ao litoral paulista de Ubatuba. Mesmo aos turistas que visitam o município sua presença é marcante, pois compõe o cenário físico da área do centro histórico, onde se concentra a maioria dos serviços turísticos ofertados, especialmente no setor de gastronomia, eventos culturais e hospedagem. 


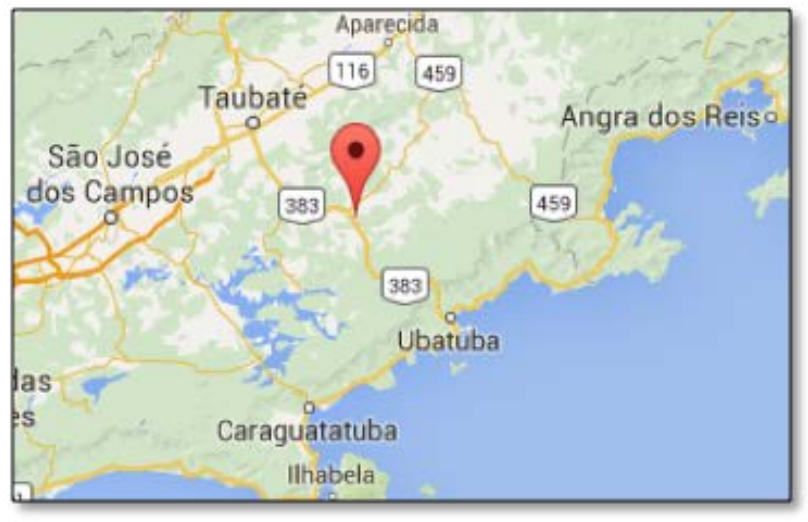

Figura 3 - Mapa da localização Fonte: Google Maps, 2016

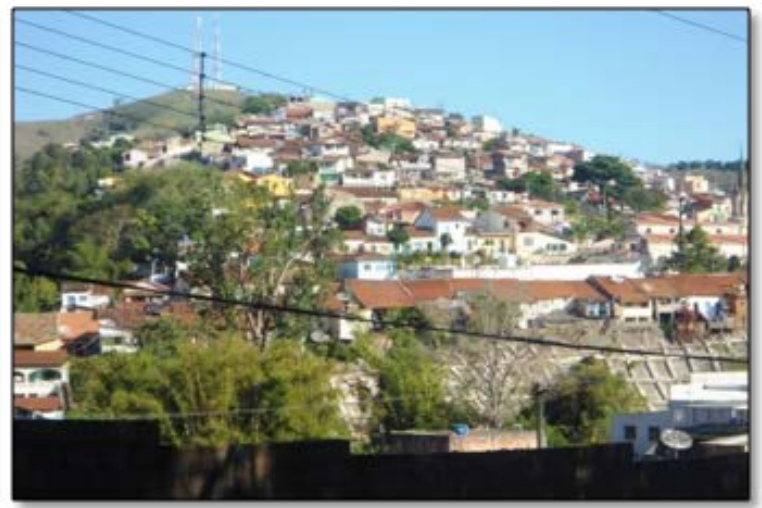

Figura 4 - Foto do Alto do Cruzeiro Fonte: Acervo das autoras, 2011

Reconstruindo a memória do bairro por meio de entrevistas com moradores mais antigos do local foi possível perceber vários momentos diferentes: um início marcado pela existência de poucas casas, quando a pobreza e as dificuldades de acesso à água e à energia elétrica estiveram muito presentes. Em oposição, atualmente, tem-se um bairro populoso composto por casas bastante próximas e ruelas que formam verdadeiras ladeiras enfrentadas diariamente por seus moradores. Segundo estimativa do Posto de Saúde da Família - Núcleo Oswaldo $\mathrm{Cruz}^{6}$, em 2011, somente o bairro Alto Cruzeiro possuía, aproximadamente, 1.054 habitantes entre os 6.180 da área urbana.

A história de formação do local está intrinsecamente atrelada à história do êxodo rural do município. A partir da década de 1950, em virtude do processo de industrialização e devido às dificuldades de modernização e mecanização da agricultura, em razão da topografia acidentada da região, muitos pequenos agricultores viram a migração para a área urbana como uma forma de escapar da situação de pobreza rural $^{7}$. Sem condições financeiras para adquirirem, por meio da compra, terrenos e/ou casas na cidade, alguns migrantes tiveram seus novos locais de moradia concedidos pelo poder público da época, outros, como o morro onde hoje é o bairro Alto do Cruzeiro, foram ocupados.

Com o objetivo da construção coletiva de um panorama geral da situação do bairro sob a óptica de seus moradores, durante a execução do que denominamos de diagnóstico rápido participativo (DRP) pudemos destacar quais são as qualidades positivas e as necessidades sentidas para a melhoria do local. A reunião ocorreu na Associação de Moradores e Amigos do Bairro Alto Cruzeiro (Amabac), existente desde o ano de 1999, cuja sede fica no morro ${ }^{8}$. Estiveram presentes 19 moradores do local, além do secretário de Turismo. Devido ao fato de possuírem graus de escolaridade variados, tendo inclusive pessoas mais idosas sem domínio da escrita, optamos pelo uso de metodologias participativas que privilegiassem as falas e que pudessem permitir que todos os presentes tivessem voz ativa durante todo o processo.

\footnotetext{
6 Devido à enchente, grande parte dos documentos e acervos municipais foi perdida. 0 posto de saúde foi o único local capaz de fornecer alguns dados sobre o bairro naquele momento.

7 Ainda que muitos tenham migrado do campo para cidade, interessante destacar que o município de São Luiz do Paraitinga já foi denominado como "o último reduto caipira" do estado de São Paulo, visto que ainda mantém alguns grupos sociais tradicionais no meio rural. Embora, atualmente, o plantio de eucalipto seja, segundo Silva (2006), o maior empregador da zona rural.

8 Casa pequena com uma sala ampla, cozinha e banheiro que funciona como espaço comunitário para realização de reuniões, ensaios e afins. No momento da pesquisa, possuía cinco computadores que atendiam à comunidade, oferecia aulas de capoeira e servia como ponto de atendimento do Posto de Saúde no bairro.
} 

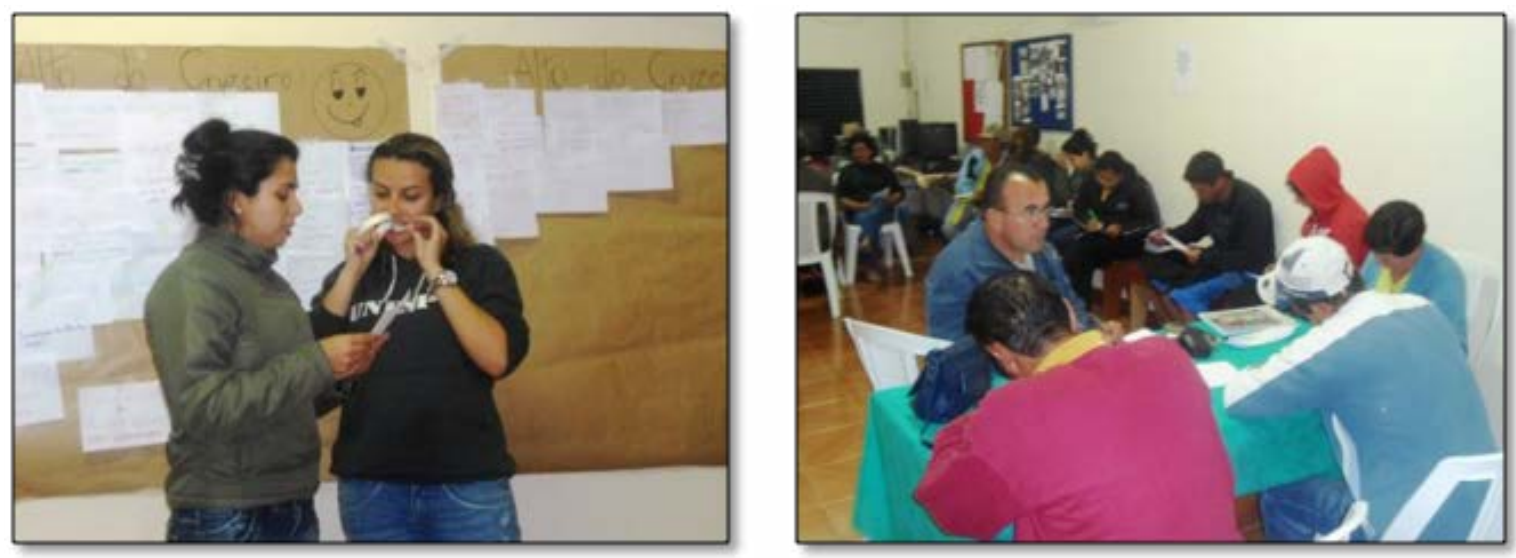

\section{Figuras 5 e 6 - Realização do DRP na Amabac Fonte: (Acervo das autoras, 2011).}

O DRP iniciou com cada participante recebendo seis papéis de duas cores previamente recortados onde deveriam anotar até três aspectos positivos sobre o bairro e até três necessidades de melhorias no local. Feito isso, iniciando pelos aspectos positivos, um a um, à frente do grupo, lia e esclarecia aos presentes sua opinião para, em seguida, colar seu papel em cartolina previamente preparada e pregada na parede (Figura 5). Importante frisarmos que a escolha dessa atividade se deu justamente para permitir que todos, sem exceção, tivessem a oportunidade de falar, evitando, assim, a concentração do poder da fala em uma única pessoa, o que poderia ocorrer, quer devido à posição social privilegiada na comunidade, ou mesmo por alguma característica da personalidade de cada um, como a ausência de inibição para falar em público. Essa pluralidade de vozes é indispensável para que se reduza ao máximo a possibilidade de futuras discordâncias entre as pessoas. Quando refletem unidas, consonâncias e discordâncias vêm à tona e, sempre que possível, consegue-se chegar a um consenso sobre o que seria uma visão coletiva sobre determinado assunto. Para tanto, é preciso saber deixar as falas fluírem, ou seja, faz-se necessário saber ouvir. Não é raro, durante esse processo, alguns mudarem as posições iniciais. Cabe ao educador/moderador deixar que isso flua, estimulando a reflexão individual e do grupo. Como as pessoas já se conheciam há bastante tempo, nesse caso, a interação e a participação fluíram bem durante a atividade, o que enriqueceu a construção do painel sobre a realidade do bairro.

Os aspectos positivos do bairro apontados pelos participantes apareceram traduzidos em palavras como: local de amizade, convívio entre as pessoas, vizinhança, honestidade, povo bom, comunidade, simplicidade, dignidade, união e solidariedade. Tais palavras reproduziram a existência de vínculos sociais fortalecidos entre os moradores, cuja convivência resultante do compartilhamento do lugar de moradia aparece como construída por vínculos de amizade e reciprocidade. Por outro lado, aspectos negativos como a necessidade de maiores investimentos em questões básicas como segurança, acesso ao bairro, limpeza, policiamento e manutenção foram apontados como expressão de descaso do poder público para com o local. Do ponto de vista simbólico, ressentiram-se do preconceito vivenciado quando circulam em outros espaços da cidade. Afirmaram que muitos olham para o bairro de maneira estigmatizada, principalmente por se tratar de um local com pessoas de baixa renda. E, por ser a questão econômica um desafio para essas pessoas, a ênfase do discurso recaiu sobre a necessidade da geração de novos empregos no município. Muitos moradores compartilham o sentimento da difícil separação entre membros da família, que se veem obrigados a migrar em busca de trabalho. Os municípios próximos, Taubaté e São José dos Cam- 
pos, por serem mais industrializados, atraem os jovens em busca de trabalho. A geração de novos postos de trabalho no município é ensejada tanto como condição para melhoria de qualidade de vida individual e familiar, quanto em uma perspectiva mais ampla e coletiva do espaço do bairro, capaz de melhorar as condições de vida de todos.

Ainda que neste dia o assunto da enchente não tenha surgido, importante destacar que durante diversas conversas informais com os moradores do bairro Alto do Cruzeiro, pudemos perceber que, embora tenham a dimensão da tragédia ocorrida, sob o ponto de vista de oportunidade de geração de emprego a enchente teve um significado positivo para aqueles que antes tinham pouco e cujas casas não foram alagadas ${ }^{9}$. Isso porque muitos dos trabalhos gerados pós-enchente, referem-se à área da construção civil, o que requer mão de obra pouco especializada, tendo empregado muitos dos moradores que antes estavam sem trabalho ou atuando fora do município, longe da família.

Após esse panorama do lugar, coube refletir sobre o turismo enquanto opção para auxiliar a reduzir os problemas visualizados. Longe de tratar o turismo como panaceia, não se pode negar que, atualmente, é o setor que mais cresce em São Luiz do Paraitinga. Tanto na zona urbana, quanto rural, pequenos comércios, pousadas e restaurantes são locais diretamente relacionados ao desenvolvimento turístico. Partindo do desejo manifesto de serem incluídos de forma mais efetiva no setor, visto que esta parece ser a opção mais cabível naquele contexto de ausência de empregos em outros setores, partimos para a construção coletiva de quais são, sob a óptica dos habitantes do lugar, seus potenciais para atração de turistas. Nesse aspecto, a vista contemplativa do centro histórico e da natureza que o circunda foi consenso entre os moradores presentes. Uma das moradoras expressou o desejo de ter o bairro como um cartão-postal da cidade, afinal, segundo ela, é a primeira paisagem que chama atenção dos turistas ao chegarem ao município.

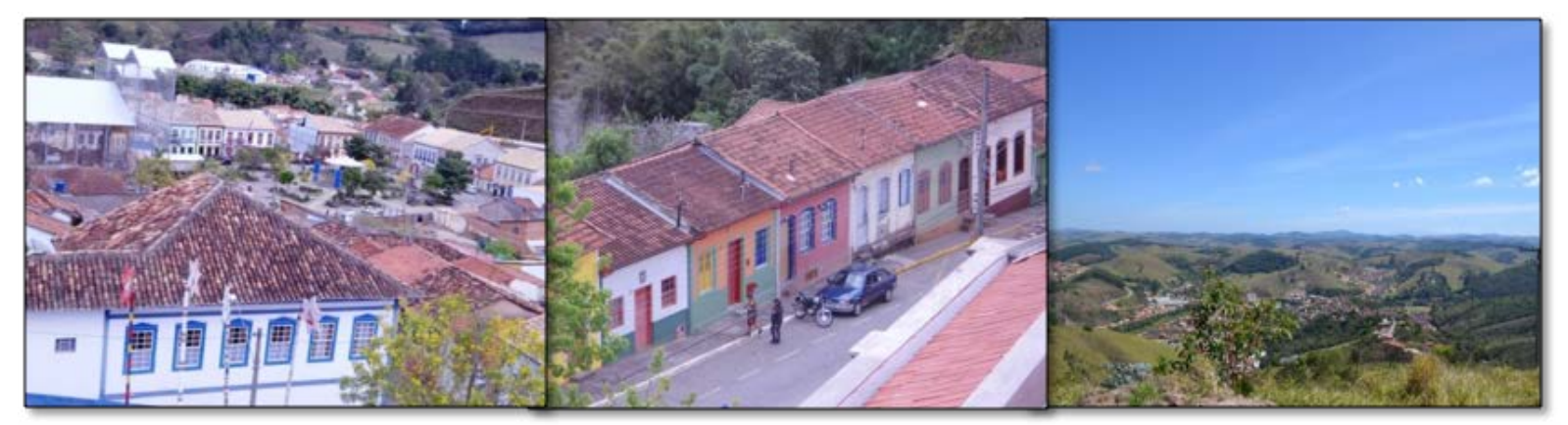

Figuras 7, 8 e 9 - Vistas contemplativas do Alto do Cruzeiro

Fonte: (Acervo das autoras, 2011).

A cultura popular ${ }^{10}$ também foi um aspecto muito reconhecido, pois, no bairro, encontram-se mestre de jongo ${ }^{11}$, cantadores de brão, responsáveis por folia de reis, grupo de congada e um contador de histó-

9 Diferente do caso de moradores do bairro que devido à sua localização em área de risco de desabamento tiveram que mudar para outra localidade construída com verba emergencial recebida pós-enchente. Para estes, a mudança parece indicar desenraizamento, mas tal questão daria outro artigo.

10 Como todo o Vale do Paraíba, São Luiz do Paraitinga também possui uma tradição de danças populares (o Moçambique e o Jongo) de profundas raízes na cultura local. Berço de grandes músicos, tem exatamente nessa arte um dos seus mais expressivos patrimônios culturais manifestado no festival de marchinhas carnavalescas estruturado na cultura do povo luizense, por meio de mitos, das lendas, da tradição na construção de bonecos gigantes e no imaginário de poetas e músicos da história da cidade (CUNHA, 2007, p. 45).

11 Espécie de samba de roda, comum nos Estados Sudoestes brasileiros. 0 Jongo costuma acontecer próximo de uma fogueira. A 
rias. Além disso, muitos foram os mitos e as lendas que ali nasceram, os quais, até hoje, são de grande importância para a cidade e estão representados por meio da tradição dos bonecões dos grupos do carnaval luizenses que atraem uma multidão de turistas todos os anos. Segundo Santos (2008), as festas de São Luiz do Paraitinga são marcadas por serem na rua, pelo improviso e pela possibilidade de inversões sociais, possuindo os luizenses uma identidade muito forte com a cultura local durante toda sua história.

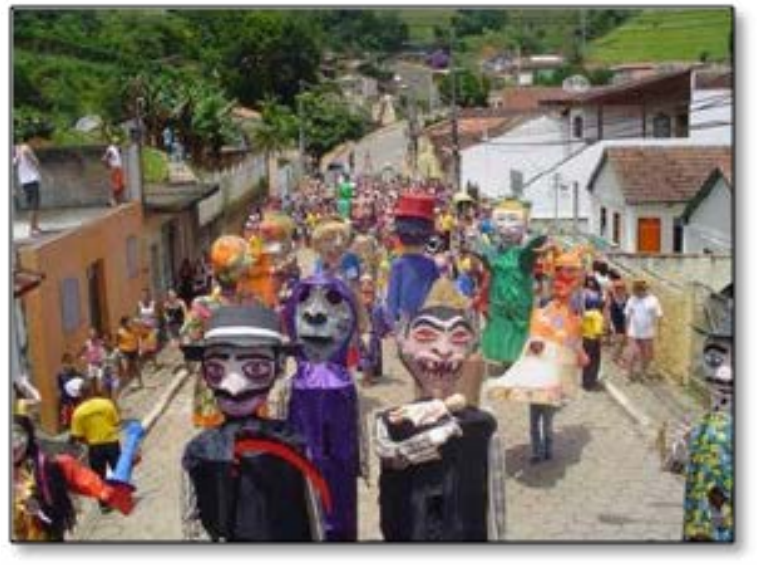

Figura 10 - Bonecões no carnaval de 2008

Fonte: Foto de Cássio Ribeiro em Santos, 2008

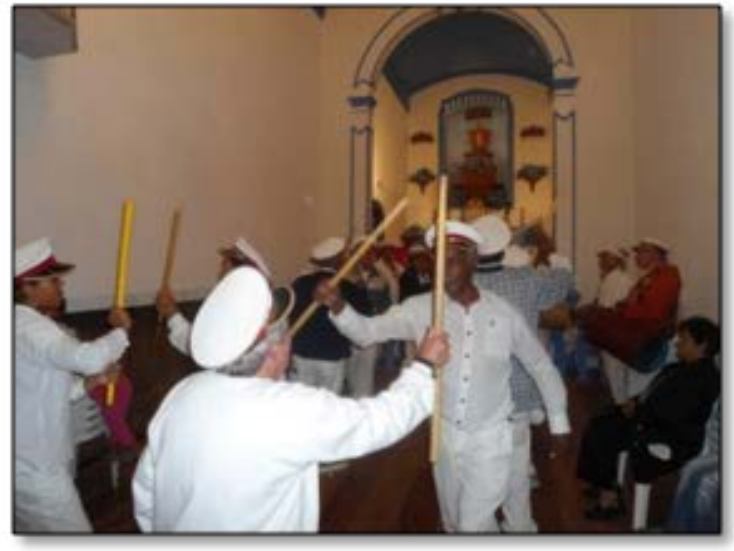

Figura 11 - Congada do Alto do Cruzeiro

Fonte: Acervo das autoras

$\mathrm{O}$ artesanato realizado no local também foi um ponto de destaque reconhecido pelos moradores do bairro, a exemplo, citaram produtos confeccionados com tecidos, produtos em madeira, balaios de cipó, peneiras, cestarias e também ícones da cultura local, como os sacis em garrafas. A gastronomia típica representada por pratos como o afogado ${ }^{12}$, cozido de carne com batata, e o pastel caipira, feito de farinha de milho, também foram mencionados, possuindo no bairro várias cozinheiras que também fazem biscoitos, pães, bolachas artesanais e doces caseiros.

A praça Benedito Alves Godoi , conhecida como “Didi”, emblemática do bairro e onde há uma grande cruz e um pequeno coreto, também foi apontada como um potencial para eventos culturais e contemplação do município. Além disso, ao pé do morro encontra-se a casa onde nasceu Oswaldo Cruz, famoso médico sanitarista brasileiro, hoje transformada em museu.

\footnotetext{
participação é livre e não há necessidade de indumentária especial. 0 canto tem papel importante, ao desafio versificado dão o nome de "ponto" e o cantador seguinte precisa "desatar o ponto" nos versos que improvisar. A coreografia é simples, uma dança de roda que se movimenta no sentido lunar (PREFEITURA MUNICIPAL DE SÃO LUIZ DO PARAITINGA, 2016). 12 Ver Monteiro; Oliveira, 2006; Pelegrini, 2011.
} 


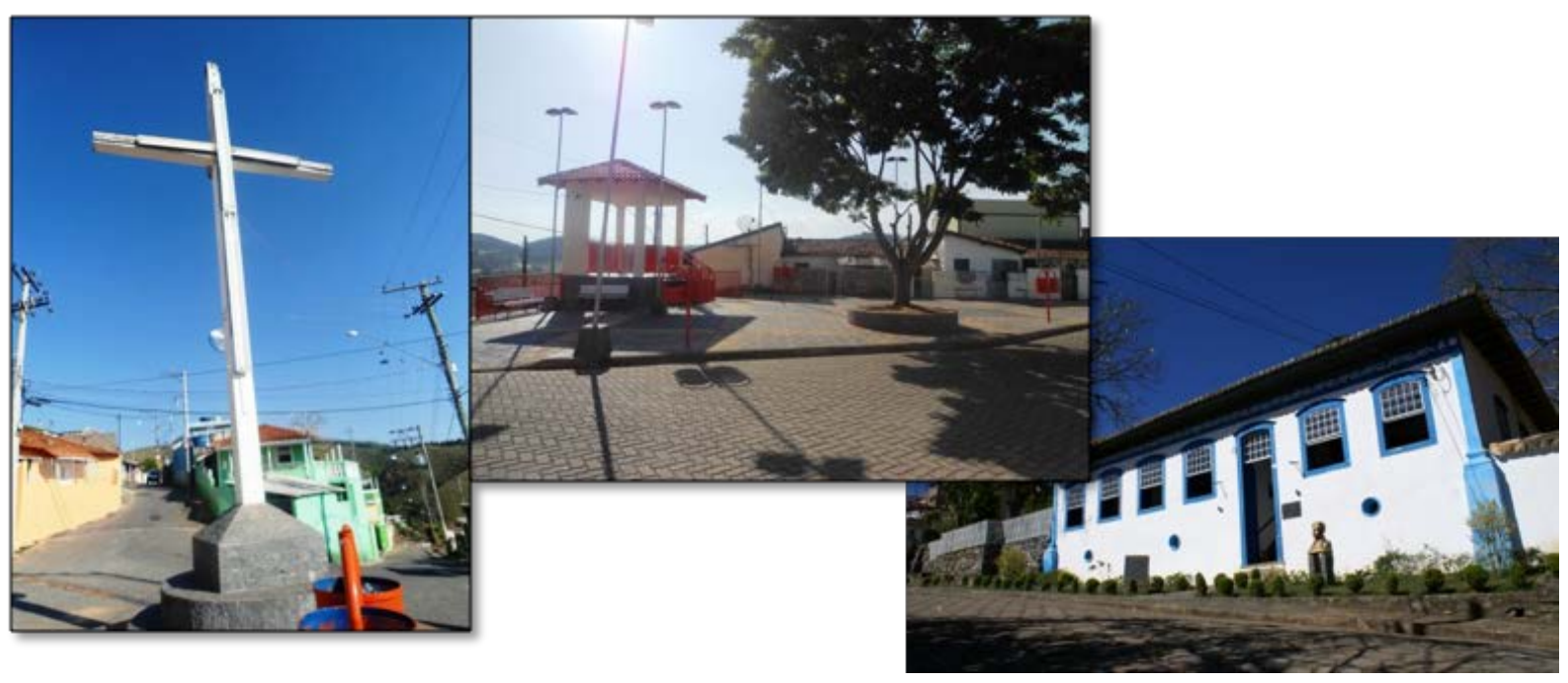

Figuras 12 e 13: Cruz e Praça Didi Fonte: (Acervo das Autoras, 2011)
Figura 14: Casa Oswaldo Cruz Fonte: (Prefeitura Municipal, 2011)

A organização comunitária, representada pela Amabac, é reconhecida pelos moradores do bairro como um importante espaço. Do ponto de vista cultural, é lá que ocorrem alguns ensaios de grupos populares e também é a Amabac a responsável pela organização de festas no bairro, sendo a principal a Festa de Santa Cruz, que foi criada com o propósito de reivindicar a negligência do poder público, uma vez que este não se importava com o bairro. Embora não se tenha o registro de quando a festa teve início, sabe-se, por meio dos relatos, que durante alguns anos ela deixou de existir e foi retomada como uma das ações da Amabac. Durante a festa, percebida como um espaço de confraternização dos moradores, ocorrem apresentações culturais, vendas de comidas e bebidas e, geralmente, tem-se a entrega gratuita ou do café com paçoca ou do afogado, práticos típicos escolhidos conforme o festeiro que a organiza.

Quando o assunto era o turismo, nas necessidades sentidas os moradores relataram a vontade de aproximação entre as atividades do centro histórico local com o bairro. Em vez de serem esporadicamente convidados para se apresentarem nos eventos na parte baixa, acreditam que o próprio bairro poderia ser palco de algumas manifestações encenadas para turistas, o que atrairia os olhares e incentivos públicos e/ ou privados para a comunidade.

\section{Considerações finais}

Como demonstrado neste trabalho, a principal reclamação dos moradores do bairro Alto do Cruzeiro é a de que as práticas de turismo ocorrem, principalmente, no centro histórico. Ficou nítido durante a atividade de diagnóstico participativo que os moradores do bairro Alto do Cruzeiro carregam um sentimento de exclusão referente ao restante da cidade quando se trata de investimentos turísticos. Alguns possuem consciência de sua riqueza cultural, valorizam suas danças, lendas e festas, mas se ressentem da ausência de empregos no município e de políticas de melhorias de infraestrutura urbana. Noutros casos, o sentimento de exclusão dos moradores era tão notório que, alguns, ao primeiro contato conosco se surpreendiam quando dizíamos estar interessadas em conhecer suas histórias. A interiorização de sua 
negação enquanto sujeitos e do estigma de pobreza a eles associados fazia com que alguns acreditassem não ter nada a contar. De todo modo, quando narravam suas trajetórias, apesar das dificuldades vividas, manifestaram um forte desejo de permanência no bairro. Morar no Alto do Cruzeiro significa, para eles, ampliar o espaço da casa para o bairro e que o transforma em um local repleto de vínculos de parentesco e amizade.

As características evidenciadas em relação aos vínculos afetivos, a riqueza cultural existente no bairro e as potencialidades apresentadas são elementos de grande valia no processo do desenvolvimento endógeno para decisão de sua inclusão (ou não) no turismo do município, vislumbrando a possibilidade (caso assim desejem os moradores locais) a partir do turismo de base comunitária.

Importante destacar que em nenhuma das falas apareceu o desejo de atuar com o segmento de hospedagem doméstica, o que do ponto de vista teórico poderia parecer oportuno, visto que, em momentos de festas locais, o setor de hospedagem costuma lotar e/ou ter preços elevados. Na realidade, o espaço privado das casas aponta para local de morada e não de negócio. Quando desejam fazer da casa um negócio, o mais comum é saírem das residências enquanto as alugam, fato mais recorrente durante o período de carnaval, quando os valores cobrados são altíssimos.

Já o bairro, enquanto espaço público, sob a óptica de seus moradores, poderia ser compartilhado com turistas na condição de fortalecimento de suas manifestações culturais locais, o que poderia trazer benefícios materiais e simbólicos. Desde que tenham respeitados seus anseios e limitações sobre o tipo de turismo e de turista desejado, acreditam que a organização comunitária, somada ao planejamento responsável do turismo, poderia proporcionar a geração de melhoria de qualidade de vida local, tanto no sentido individual, como no sentido coletivo do espaço do bairro, melhorando as condições de vida de todos.

Todavia, é nítido que apenas a vontade comunitária não é o suficiente para a inclusão dos moradores do Alto do Cruzeiro no turismo de São Luiz do Paraitinga, afinal, muitas são as dificuldades que dependem de políticas públicas que garantam desde melhorias básicas no local, como água e esgoto, até o reconhecimento da necessidade de investimentos voltados para o desenvolvimento turístico com responsabilidade e inclusão social. De acordo com os projetos apresentados no Plano Diretor Participativo do município, sancionado em 2010, a intervenção do poder público para aquela localidade é impulsionar, de alguma forma, o desenvolvimento do turismo. Algumas ações foram realizadas como o caso de melhorias na praça Didi e também nas vias de acesso do bairro. Mas, para que ocorra o efetivo desenvolvimento endógeno no local, é necessário, além do fortalecimento das políticas públicas locais, uma maior aproximação entre moradores e planejadores e gestores públicos.

Assim, esperamos que este trabalho contribua ao vislumbrar uma possibilidade de desenvolvimento do turismo de base comunitária, que respeite os anseios dos moradores e contribua para romper as barreiras de inclusão social. Afinal, ao que tudo indica, os vínculos afetivos com o espaço de moradia somados à riqueza cultural existente vislumbram a possibilidade de uma prática turística mais solidária e menos competitiva entre os moradores, transpondo de uma cultura de isolamento para uma cultura de cooperação. 


\section{Referências}

AB'SABER, A. 0 sítio urbano de São Luiz do Paraitinga e a tragédia das grandes cheias do rio. In: BIZELLI, J. L.; ALVES, J.X. S. (Org.). Gestão em Momento de Crise: programa Unesp para desenvolvimento sustentável de São Luiz do Paraitinga. São Paulo: Cultura Acadêmica, 2011. p. 163-177.

AGUIAR, M. São Luiz do Paraitinga (usos e costumes). 2. ed. São José dos Campos: JAC, 2011.

BENI, M. C. Políticas e planejamento de turismo no Brasil. São Paulo: Aleph, 2006.

BIZELLI, J.L.; ALVES, J.X. S. (Org.). Gestão em Momento de Crise: programa Unesp para desenvolvimento sustentável de São Luiz do Paraitinga. São Paulo: Cultura Acadêmica, 2011.

BRANDÃO, C. R. Repensando a pesquisa participante. São Paulo: Brasiliense, 1999.

CAMPOS, A.; DELAMARO, M. C. Pesquisa, extensão e parcerias em São Luiz do Paraitinga: refletindo sobre passados e futuros carnavais. In: BIZELLI, J. L.; ALVES, J. X. S. (Org.). Gestão em Momento de Crise: programa Unesp para desenvolvimento sustentável de São Luiz do Paraitinga. São Paulo: Cultura Acadêmica - Unesp, 2011, v. 1, p. 75-95.

CAMPOS, J. T. A imperial São Luiz do Paraitinga: história, cultura e educação. Taubaté: Resolução Gráfica, 2011.

CORIOLANO, L. N. M. T. O turismo comunitário no Nordeste brasileiro. In: BARTHOLO, R.; SANSOLO, D. G.; BURSZTYN, I. Turismo de Base Comunitária: diversidade de olhares e experiências brasileiras. Rio de Janeiro: Letra \& Imagem, 2009. p. 277-288.

CUNHA, J. S. R. Turismo em cidades com patrimônio histórico tombado: estudo de caso da cidade de São Luiz do Paraitinga. Trabalho de Conclusão de Curso. Graduação em Turismo, Universidade Estadual Paulista, Rosana, 2007.

FREIRE, P. Extensão ou comunicação? 8. ed. Rio de Janeiro: Paz e Terra, 1983.

FREIRE-MEDEIROS, B. Gringo na Laje: produção, circulação e consumo da favela turística. Rio de Janeiro: Editora FGV, 2009.

GASTAL, S.; MOESCH, M. Turismo, políticas públicas e cidadania. São Paulo: Aleph, 2007.

GRÜNEWALD, R. Os índios do descobrimento: tradição e turismo. Rio de Janeiro: Contra Capa Livraria, 2000.

HOBSBAWN, E.; RANGER, T. A invenção das tradições. Rio de Janeiro: Paz e Terra, 1984.

IBGE - Instituto Brasileiro de Geografia e Estatística, Censo Demográfico 2010. Disponível em: 〈http:// www.ibge.gov.br/cidadesat/link.php?codmun=355000 . Acesso em: 19 set. 2011.

IRVING, M. Reinventando a reflexão sobre turismo de base comunitária: inovar é possível. In: BARTHOLO, R.; SANSOLO, D. G.; BURSZTYN, I. Turismo de Base Comunitária: diversidade de olhares e experiências brasileiras. Rio de Janeiro: Letra \& Imagem, 2009. p. 108-121.

KRIPPENDORF, J. Sociologia do turismo: para uma nova compreensão do lazer e das viagens. São Paulo: Aleph, 2009.

MONTEIRO, P. C.; OLIVEIRA, E. R. 0 prato do Divino: um estudo sobre a culinária na Festa do Divino Espírito Santo, em São Luís do Paraitinga. XVIII Encontro Regional de História, Assis, 2006. Disponível em: 〈http://www.anpuhsp.org.br/sp/downloads/CD\%20XVIII/pdf/PAINEL\%2oPDF/Paula\%20 Camila\%2oMonteiro.pdf〉. 
PELEGRINI, S. C. A. Tradições e histórias locais: as esperanças nas bandeiras do Divino em São Luiz de Paraitinga (São Paulo/Brasil). Patrimônio e Memória, v. 7, n. 1, p. 231-256, jun. 2011.

PREFEITURA MUNICIPAL DE SÃO LUIZ DO PARAITINGA. A cidade: manifestações culturais. Disponível em: 〈http://www.saoluizdoparaitinga.sp.gov.br/site/a-cidade/manifestacoes-culturais/〉 Acesso em: 2 jul. 2011.

RAMIRO, P. A. 0 turismo na agricultura familiar. TRAF: uma análise do conceito. Anais da $53^{a}$ Reunião da Sociedade Brasileira de Economia, Administração e Sociologia Rural, João Pessoa, 2015. Disponível em: 〈http://icongresso.itarget.com.br/tra/arquivos/ser.5/1/5397.pdf〉.

. Unesp em Campo: o papel da universidade para o (re)conhecimento local. In: SAGAWA, R. (Org.). Os Enlaces da Economia Solidária. Curitiba: CRV, 2012.

RIBEIRO, G. Turismo de base comunitária. Revista Global Tourism, v. 4, n. 2, nov. 2008. Disponível em: 〈http://www.periodicodeturismo.com.br/site/artigo/pdf/Turismo\%2oComunit\%C $3 \%$ A1rio.pdf . Acesso em: 05 out. 2011.

SANSOLO, D. G.; BURSZTYN, I. Turismo de base comunitária: potencialidade no espaço rural brasileiro. In: BARTHOLO, R.; SANSOLO, D. G.; BURSZTYN, I. Turismo de Base Comunitária: diversidade de olhares e experiências brasileiras. p.142-161. Rio de Janeiro: Letra \& Imagem, 2009.

SANTOS, J. R. C. A festa do divino de São Luiz do Paraitinga: o desafio da cultura popular na contemporaneidade. Dissertação (Mestrado). Programa de Pós-Graduação de História Social. Universidade de São Paulo, São Paulo: 2008.

A cultura como protagonista do processo de reconstrução da cidade de São Luiz do Paraitinga/SP. Tese (Doutorado). Programa de Pós-graduação em História Social. Universidade de São Paulo, 2015.

SANTOS, M. J.; RICCI, F. Memória e patrimônio cultural: a reconstrução de São Luiz do Paraitinga. In: XX ENCONTRO REGIONAL DE HISTÓRIA: HISTÓRIA E LIBERDADE. Franca, 2010.

SCHNEIDER, S. Turismo em comunidades rurais: inclusão social por meio de atividades não agrícolas. In: MINISTÉRIO DO TURISMO. Turismo social: diálogos do turismo. Uma viagem de inclusão. Rio de Janeiro: IBAM, 2006. p. 264-293.

SILVA, F. F. Identidade cultural, culturas subalternas e o patrimônio arquitetônico: a experiência de São Luiz do Paraitinga. Dissertação (Mestrado em Ciências da Comunicação) - Escola de Comunicação e Artes, Universidade de São Paulo: 2006.

SILVA, M. J. D. Soluções hidráulicas para a proteção de áreas de riscos urbanos. In: BIZELLI, J. L.; ALVES, J. X. S. (Org.). Gestão em Momento de Crise: programa Unesp para desenvolvimento sustentável de São Luiz do Paraitinga. São Paulo: Cultura Acadêmica, 2011. p. 03-17.

SINGER, P. Introdução à economia solidária. São Paulo: Editora Fundação Perseu Abramo, 2002.

SOUZA, A. S. São Luiz do Paraitinga: reconstrução de uma cidade e de um patrimônio. Projeto experimental (Conclusão de Curso) - Habilitação em Jornalismo, Curso de Graduação em Comunicação Social, Faculdades Integradas Rio Branco, São Paulo, 2010.

TOMAZIN, M. 0 umbigo foi plantado dentro de casa: história e memória do Alto do Cruzeiro. Trabalho de Conclusão de Curso. Graduação em Turismo, Universidade Estadual Paulista, Rosana, 2011. 